\title{
Aspectos conceituais, comportamentais e culturais do orçamento como ferramenta gerencial
}

\author{
Adriane Fagundes Silva \\ Mestrado em Ciências Contábeis pela Universidade Estadual do Rio de Janeiro - UERJ \\ Professora do Centro Universitário UNILASALLE/RJ \\ Rua Gastão Gonçalves, 79. Santa Rosa. Niterói/RJ. CEP: 24240-030 \\ E-mail: adriane_fagundes@yahoo.com.br \\ Graduação em Ciências Contábeis pelo Centro Universitário UNILASALLE/RJ \\ Analista Contábil Junior da empresa Domingues e Pinho Contadores Ltda \\ Avenida Rio Branco, 311. Centro/RJ. CEP: 2004-000 \\ E-mail: jaiiir.nunes@hotmail.com
}

\section{RESUMO}

As organizações têm buscado desenvolver sistemas acurados de controle diante da acirrada competição que as compele a formular estratégias adequadas ao seu propósito. Nesse contexto, o orçamento representa uma ferramenta gerencial amplamente utilizada pelas empresas, já que auxilia no estabelecimento de metas, na avaliação de resultados e na identificação de áreas que necessitam de iniciativas. Mais do que enfatizar os aspectos conceituais e técnicos do orçamento, o presente estudo tem o propósito de enfocar a abordagem comportamental e cultural presente nesta ferramenta gerencial, visando explicitar os valores nele contidos e confrontá-los com os da cultura brasileira. Esta pesquisa baseia-se no conceito desenvolvido por pesquisadores que defendem que as ferramentas de gestão em geral, carregam valores de sua própria cultura de forma que condições particulares, de maneira geral, demandam soluções específicas, que podem se tornar inadequadas se aplicadas em outros contextos. Foi realizada uma revisão da literatura considerando os principais pesquisadores que versam sobre o tema.

Palavras-Chaves: Orçamento. Aspectos Comportamentais. Aspectos Culturais.

Conceptual, behavioral and cultural issues of budget as a management tool 


\section{ABSTRACT}

Organizations have been trying to develop accurate systems of control in the face of fierce competition that compels them to formulate appropriate strategies to their purpose. In this context, budget represents a management tool widely used by companies, which assists in setting goals, evaluating results and identifying areas that need initiatives. More than emphasize the conceptual and technical aspects of the budget, this study aims to focus the cultural and behavioral approach presented in this management tool in order to clarify the values it contains and compare them with those of Brazilian culture. This research is based on the concept developed by researchers who argue that the management tools in general, carry values of their own culture so that the particular conditions in general, require specific solutions, which may become inadequate if applied in other contexts. A literature review regarding some researchers was performed to deal with the issue.

Keywords: Budget. Behavioral Aspects. Cultural Aspects.

\section{INTRODUÇÃO}

Em um contexto socioeconômico turbulento, as organizações têm buscado desenvolver sistemas de controle bastante dinâmicos diante da acirrada competição e rápida disseminação de novas técnicas e paradigmas que implicam em mudanças rápidas nas estratégias assim como em suas estruturas organizacionais (GOMES; SALAS, 2001). O orçamento como ferramenta gerencial, vincula-se à consecução das estratégias definidas pela organização, afim de que os chamados centros de responsabilidade atuem separadamente para alcançar seus objetivos e consequentemente os objetivos globais.

Literatura sobre o tema enfatiza que a consecução do orçamento se vincula à formulação de estratégias, planejamento e controle, como uma ferramenta eficaz para o êxito das empresas. "O orçamento se torna uma ferramenta importante para quantificar em termos financeiros os anseios declarados no planejamento estratégico, nos planos táticos e operacionais" (ROCHA; ROCHA, 2006, p. 2). 
O orçamento é adotado amplamente pelas companhias com a finalidade básica de controlar suas finanças, e a consequência principal é a obtenção de um planejamento mensal e/ou anual e posterior avaliação entre o orçado e o realizado. $O$ orçamento como uma ferramenta gerencial promove maior controle de gastos, sob uma administração previamente definida e organizada, gerando uma estabilidade tanto para empresa quanto para seus colaboradores, valorizando-os.

Gomes e Salas (2001) reforçam o argumento ao mencionar que em organizações orientadas estrategicamente para a liderança de custos, o sistema de controle deve ser desenhado atribuindo maior ênfase à formalização, à definição de indicadores quantitativos, ao estabelecimento de padrões e ao cálculo de variações orçamentárias, tendo em vista que a forte competitividade obriga a ter estratégias que combinam tanto a diferenciação como a liderança em custos. Não há dúvida, portanto, sobre a relevância do orçamento como instrumento gerencial presente nas organizações, o que justifica o estudo em questão.

No entanto, há uma discussão muito atual e pertinente sobre a influência dos aspectos comportamentais e culturais presentes nas práticas gerenciais, que, muitas vezes, carregam valores dos pesquisadores que as desenvolveram, que conforme Fonseca (2007) não podem ser aplicadas em qualquer cultura sem uma análise que aponte seus valores implícitos, ou seja, identifique seus pressupostos. Neste sentido, vários pesquisadores (TANURE; PRATES, 1996; GOMES; SALAS, 2001; FONSECA, 2007) propõem-se a analisar os sistemas de controle gerencial e, por conseqüência, as ferramentas gerenciais tal qual o orçamento - com um olhar voltado para a cultura em que a organização está inserida, na medida em que acreditam que as características do modelo adotado devem ser compatíveis não só com contexto interno da organização, mas também com seu contexto social.

Portanto, o objetivo deste estudo foi discutir uma das ferramentas gerenciais, o orçamento, do ponto de vista conceitual, comportamental e cultural, a partir de uma revisão da literatura sobre o tema. Para tal, está estruturado em quatro seções. Dando prosseguimento a esta seção inicial, a segunda seção procura analisar os aspectos 
conceituais e técnicos do orçamento; a terceira seção apresenta uma exposição sobre a consideração dos elementos comportamentais e culturais que interferem na aplicação das ferramentas gerenciais; e na última seção procurou-se fazer uma análise comportamental e cultural presentes no orçamento e se estes são compatíveis com os da cultura brasileira.

\section{ASPECTOS CONCEITUAIS E TÉCNICOS DO ORÇAMENTO}

Sanvicente e Santos (2000) afirmam que a atividade de controle em uma organização pressupõe o acompanhamento da execução de atividades de maneira mais rápida possível, e a comparação do desempenho efetivo com o planejado. Tornase evidente que a função de controle não se esgota no acompanhamento puro e simples, como também envolve a geração de informações para tomadas de decisão de avaliação e eventual correção do desempenho alcançado, proporcionalmente ao seu afastamento em relação ao considerado desejável e satisfatório.

Nesse sentido, pode se definir que o orçamento, conforme assinalado por Tung (1994) consiste na apresentação dos resultados antecipados de um plano, projeto ou estratégia. "Serve como um mapa rodoviário por meio do qual se alcançam os objetivos" (HORNGREN et al, 2004, p. 229). O orçamento gera um plano de operações para atingir determinado objetivo, mediante a locação coordenada dos recursos e meios disponíveis em um determinado horizonte de tempo.

Sobre este aspecto, Garrison e Noreen (2001) destacam que o orçamento deve ser utilizado como instrumento positivo para ajudar no estabelecimento de metas, na avaliação dos resultados operacionais e na identificação das áreas que necessitam de iniciativas e atenção extras, ao invés de ser empregado como instrumento de pressão.

Cardoso et al. (2007) reiteram que o orçamento como ferramenta gerencial exerce outras funções:

1. Usado para coordenar e comunicar prioridades estratégicas; 
2. Alinhamento de interesses, que quando utilizados com sistemas de recompensa, facilita o acréscimo do comprometimento da baixa gerência com as prioridades estabelecidas pela alta gerência;

3. Aprendizagem e interação entre diversos níveis gerenciais e áreas.

Tung (1994) destaca a determinação das áreas de responsabilidades para cada função da empresa de forma controlável. O orçamento serve de válvula de segurança para o gerenciamento. As empresas dotadas de um sistema orçamentário bem definido gozam sempre de maior prestígio junto às fontes de financiamento e o orçamento também impõe o fortalecimento da administração, aperfeiçoando os seus sistemas de registro, análise, relatórios, ou seja, elementos indispensáveis para a tomada de decisão.

Complementando o argumento, Horngren (2000, p. 125) destaca o uso quase universal da ferramenta orçamentária e afirma que "os sistemas de orçamentos fazem com que os administradores olhem para frente, o que os coloca numa melhor posição para aproveitar oportunidades".

Atkinson et al. (2000) afirmam que o orçamento das empresas reflete as condições quantitativas de como alocar recursos financeiros para cada subunidade organizacional, com base nas suas atividades e nos objetivos de curto prazo, podendo ser considerado como expressão quantitativa das entradas de dinheiro para determinar se um plano financeiro atingirá as metas organizacionais.

Leite et al. (2005) apontam o orçamento também com uma função de controle. 
Outra finalidade do orçamento é a possibilidade de indicar a existência de problemas e servir como ferramenta para encontrar as respectivas soluções. Isso é verificável nas empresas que fabricam produtos sazonais e, portanto, precisam aplicar grandes quantias de dinheiro no processo de embalagem de seus produtos, os quais serão vendidos durante o ano, quando, então, a empresa recuperará o dinheiro aplicado. $O$ orçamento prevê esse ciclo e gera informação de que a empresa terá que providenciar os recursos necessários para financiar a formação dos estoques no início desse ciclo. Se o planejamento orçamentário indicar que o potencial de produção não acompanhará as metas de venda, assim, o orçamento contribui para que a empresa desenvolva a habilidade de antecipar problemas potenciais. (LEITE et al., 2005, p.4).

O orçamento empresarial poderá ser caracterizado através das seguintes premissas básicas, segundo (ZDANOWICZ, 1984 apud MARTINS et al. , 2004, p.7):

1. A projeção das estimativas de vendas, custos, matérias-primas, mão-de-obra, bem como dos demais custos e despesas operacionais da empresa;

2. A flexibilidade na aplicação deverá ser adaptável as mudanças de mercado e cenários;

3. E o envolvimento de todos no comprometimento em alcançar as metas fixadas no plano.

Em geral, a literatura em questão classifica os orçamentos em mestre (estáticos ou inflexíveis) e flexíveis. Segundo Horngren et al. (2004, p. 232) o orçamento mestre resume as atividades planejadas de todas as subunidades de uma organização, incluindo as previsões de vendas, despesas, recebimentos, e desembolsos de caixa e o balanço patrimonial, podendo consistir de "doze orçamentos mensais para o ano, ou talvez, orçamentos mensais para apenas o primeiro trimestre e orçamentos trimestrais para os três trimestres remanescentes do ano". Em suma, são considerados estáticos ou inflexíveis porque consideram apenas um nível de um dado tipo de atividade.

Já "o orçamento flexível é aquele que se ajusta para as mudanças no volume de vendas e outras atividades direcionadoras de custos. O orçamento flexível é idêntico ao 
orçamento mestre no formato, mas os gestores podem prepará-lo para qualquer nível de atividade" (HORNGREN et al., 2004, p. 266).

Garrison e Noreen (2001) defendem o uso do orçamento flexível, destacando deficiências do orçamento estático. Segundo os autores, na avaliação de desempenho, no orçamento flexível "os custos reais são comparados com os custos que deveriam ter ocorrido no período para o nível real de atividade, e não com os custos do orçamento original". Horngren et al. (2004, p.269) reforçam o argumento ao afirmar que "o intento de usar o orçamento flexível para avaliação de desempenho é isolar os efeitos inesperados nos resultados reais, que podem ser corrigidos se adversos ou ser melhorados se benéficos."

Com relação à implantação do orçamento, Sanvicente e Santos (2000) identificam dois pontos relevantes: o primeiro deles é iniciar o processo pelas áreas onde estejam concentrados os entusiastas, de forma que o êxito dessas áreas facilite a aceitação das demais de forma a fazer com que o setor de orçamento tenha contato direto com as áreas operacionais, possibilitando melhor entendimento das realidades da atividade produtiva e consecutivo alinhamento das projeções.

Complementando o argumento, Welsch (1983 apud ROCHA; ROCHA, 2006) afirmam que:

\footnotetext{
A participação tende a aumentar o grau de comprometimento do indivíduo; esse comprometimento aumenta a motivação do indivíduo; a motivação orientada para o trabalho tende a levar os administradores a trabalhar mais e com maior produtividade; e o trabalho mais árduo e produtivo dos administradores tende a contribuir para a prosperidade da empresa; portanto, a participação é boa.
}

Nesse sentido, Atkinson et al. (2000), em uma abordagem comportamental do orçamento nas organizações, alertam para diferentes formas de elaboração do orçamento. Segundo os autores, o mesmo pode ser autoritário, quando imposto pela administração, participativo quando conta com a colaboração conjunta dos empregados 
Aspectos conceituais, comportamentais e culturais do orçamento como ferramenta gerencial Adriane Fagundes Silva, Jair Nunes

em sua elaboração e consultivo, onde os gerentes consultam os empregados, mas determinam as metas.

\section{ABORDAGEM COMPORTAMENTAL E CULTURAL: PREMISSAS VERSUS VALORES}

Conforme citado por Silva (2010), nas últimas décadas, pesquisadores renomados começaram a estudar o papel da cultura nacional no desenho do controle de gestão das organizações, pressupondo que a cultura nacional se configura como fator importante na administração das empresas. Dentro destes estudos, conceitua-se a chamada "corrente divergente" como aquela que:

[...] têm como propósito analisar o impacto dessas diferenças sobre os estilos de liderança, processos de negociação, gestão de pessoas, motivação e gestão de conflitos sob a premissa de que condições particulares, de maneira geral, demandam soluções específicas, que podem se tornar inadequadas se aplicadas em outros contextos (SILVA, 2010).

Segundo Hampden-Turner e Trompennars (1994 apud FONSECA, 2007), os principais valores da ideologia capitalista confundem-se com os valores da sociedade norte-americana, valores estes consagrados pela busca da liberdade, individualismo, dentre outros, de forma que práticas administrativas aceitas universalmente e que passaram a ser encaradas como a única escolha econômica do sistema capitalista, reflete, na realidade, valores norte-americanos.

Neste conceito, poder-se-á fazer uma análise do orçamento como uma ferramenta gerencial que conforme Fonseca (2007), baseado no chamado "modelo de Anthony" - fazendo referência aos pesquisadores Anthony e Govindarajan - possui as seguintes características:

$>$ Coordena-se com o plano estratégico; 
> As receitas e as despesas são realinhadas para corresponderem a centros de responsabilidade, mostrando como espera-se que as despesas sejam incorridas por executivo;

$>$ A preparação do orçamento é essencialmente um processo de negociação entre cada gerente de centro de responsabilidade e seu superior hierárquico;

$>$ O resultado das negociações é uma definição de consenso a respeito das despesas a serem realizadas durante $o$ ano.

A linha de pesquisa que analisa a prática do orçamento do ponto de vista cultural define que o orçamento é bastante disseminado entre as empresas porque garante um planejamento financeiro por um período (normalmente um ano), na qual permite-se o acompanhamento entre os valores reais com aqueles orçados. Dentre vários aspectos culturais a serem analisados, destaca-se ilustrativamente a questão da distância hierárquica definida como "a medida do grau de aceitação, por aqueles que têm menos poder nas instituições e organizações de um país" (HOFSTEDE, 1997, p. 42), ou seja, conceito extremamente ligado ao grau de dependência e subordinação entre partes. A validade do orçamento como instrumento gerencial é observado em culturas onde as distâncias hierárquicas são encurtadas, como é o caso dos Estados Unidos, "berço" do desenvolvimento do orçamento. A preparação do orçamento pressupõe um processo de negociação de cada gestor com seu superior hierárquico, com uma independência para negociar, dando a ideia de confronto, na qual cada indivíduo, responsável por seus atos, defenderá seus pontos de vista com autodeterminação (FONSECA, 2007).

A autora argumenta que o pressuposto de existência de negociação entre as partes revela traços de valores encontrados na sociedade norte-americana, pois se torna necessário que os subordinados sejam suficientemente independentes para negociar significativamente com o chefe, o que ocorreria nos EUA, que apresentam baixos índices de distância do poder, ou seja, os membros menos poderosos das instituições e organizações não aceitam com facilidade que o poder fique distribuído desigualmente. 
Já a sociedade brasileira é marcada por grandes distâncias de poder, em que as relações pessoais são muito importantes. Segundo Tanure e Prates (1996), a combinação da concentração do poder e do personalismo (atração pessoal), que resulta no paternalismo, traria algumas consequências para o processo de negociação dentro das organizações. Logo, os pressupostos básicos para a consecução do orçamento seriam comprometidos pelos valores presentes na cultura brasileira.

\section{ANÁLISE DOS ASPECTOS COMPORTAMENTAIS E CULTURAIS DO ORÇAMENTO}

Para uma análise mais profunda, a exemplo do trabalho de Fonseca (2007), apresentar-se-á uma leitura do orçamento à luz dos aspectos presentes na cultura brasileira.

\subsection{Função planejamento do orçamento}

Frezatti (2006) assinala que a administração deve compreender o papel do planejamento nos negócios, saber da importância e benefícios que ele traz a organização, dedicando os recursos no seu desenvolvimento, apoiando nas várias etapas e cobrando resultados.

$\mathrm{Na}$ função planejamento, na qual os orçamentos se relacionam, Leite et al. (2008, p.2) afirmam que "o orçamento empresarial é um instrumento que contempla formalmente as metas e objetivos, funcionando como meio para comunicar de onde ir e para onde a empresa está caminhando."

Estes autores salientam ainda que o orçamento empresarial não representa apenas uma ferramenta para limitar e controlar gastos, mas também uma forma de dar importância nas operações e finanças da empresa, antecipando os problemas, sinalizando metas e objetivos que necessitem de cuidados, auxiliando gestores nas tomadas de decisões no intuito de cumprir as estratégias e missões da empresa. 
Reforçando o argumento, Vasconcelos (2004 apud ROCHA; ROCHA, 2006) afirmam que a organização e o planejamento da construção do orçamento são dois fatores determinantes para o sucesso da implementação da ferramenta. A companhia precisa estar estruturada para gerar e compilar todas as peças orçamentárias. Neste sentido, destacam quatro práticas que tendem a facilitar o processo de implementação: (1) Definição da equipe a ser envolvida; (2) Identificação dos responsáveis setoriais; (3) Discussão sobre as formas de treinamento necessárias; e (4) Construção de um cronograma de reuniões.

A capacitação técnica dos envolvidos na confecção do orçamento e na própria gestão da empresa é outro ponto crítico. Frezatti (2000) afirma que três aspectos precisam ser enfatizados: o conhecimento do negócio, o conhecimento da técnica de planejamento e controle e a clareza quanto o que esperar em termos de resultados.

A formulação de estratégias, definição de objetivos e planejamento, pressupõe, conforme descrito por Adler e Jelinek (1991 apud FONSECA, 2007) uma preferência pelo controle, que, por exemplo, na cultura americana, por acreditarem que têm influência sobre o ambiente, planejam seu trabalho, decidindo o que completarão e quando. Já no Brasil, por outro lado, alguns estudos apontam uma tendência ao fatalismo na cultura brasileira, contrapondo-se à cultura americana. Percebe-se uma crença no poder do destino, da sorte e, portanto, de falta de controle.

A passagem de Tanure e Prates (1996, p. 49) ilustra bem este fato:

Deus e o tempo são para nós recursos inesgotáveis. Um Deus que é brasileiro, a quem está entregue a nossa sorte, pois caberá a ele dar uma solução aos nossos problemas, bastando, para isso só esperar. Esperar o tempo de amanhã e ir dando tempo ao tempo para que os imponderáveis atuem mais livremente e que o assunto se resolva com o mínimo de interferência. A nossa experiência não é um empreendimento que deverá ser bem-sucedido em prazo hábil, como o é para os americanos. É sim, um bilhete de loteria, no qual vale a pena apostar, pois pode ser premiado um dia. 
Aspectos conceituais, comportamentais e culturais do orçamento como ferramenta gerencial Adriane Fagundes Silva, Jair Nunes

\subsection{Envolvimento das partes, comunicação e motivação}

Segundo Martins et al. (2005), as empresas traçam metas com o intuito de atingilas, com a finalidade de evitar prejuízos. As metas são planejadas através da programação dos gastos com base no orçamento anual. Salientam ainda que a participação de dirigentes e funcionários seja de fundamental importância na elaboração do orçamento.

O contador e a alta gestão devem demonstrar aos gestores e empregados como o orçamento pode ajudar a alcançar melhores resultados (HORNGREN et al., 2004). Somente dessa maneira os orçamentos se tornarão uma ajuda positiva na motivação dos empregados em todos os níveis para trabalhar em direção às metas, ao conjunto de objetivos, mensurarem os resultados de forma acurada e dirigir a atenção para as áreas que precisam de investigação.

Os autores afirmam, ainda, que a qualificação do pessoal envolvido na confecção do planejamento orçamentário é fundamental, e destacam que a composição de um comitê é uma alternativa interessante para reduzir os custos da fase de planejamento. Esse comitê funcionaria como alicerce da orçamentação, atuando principalmente na análise das séries históricas e na formação de expectativas de custos, despesas e receitas; o objetivo do comitê é auxiliar tecnicamente os gestores no planejamento orçamentário. Com relação à identificação dos responsáveis de cada setor, é interessante identificar além do gestor da área, potenciais colaboradores, "os quais devem atuar na proposição de sugestões para melhoria contínua dos processos e procedimentos. O trabalho de conscientização deve começar pelos entusiastas" (VASCONCELOS, 2004 apud ROCHA; ROCHA, 2006, p. 3). Assim, os funcionários que apresentarem níveis de aceitação acima da média devem ser envolvidos no planejamento de suas respectivas áreas ou mesmo convidados a integrar o comitê.

Rocha e Rocha (2006) discutem sobre a importância da qualificação do pessoal envolvido na confecção do planejamento orçamentário. Um dos pontos a serem observados que é de extrema relevância é a resistência para com o orçamento por parte dos colaboradores da empresa destacando como principais motivos: a resistência 
a mudanças, falta de compreensão do programa e de seu funcionamento, expectativa de maior pressão, aversão à aferição do desempenho, discordância quanto à necessidade de planejamento, preferência por abordagens menos formais no processo administrativos e a preocupação em relação às conseqüências possíveis e seus impactos nos indivíduos e grupos.

Para minimizar estes efeitos, Garrison e Noreen (2001) destacam que o sucesso de um programa de orçamento está ligado à aceitação e ao apoio da alta direção; o incentivo e a orientação devem partir do nível mais alto.

Conforme a interpretação de Fonseca (2007), no que tange ao envolvimento dos funcionários, na cultura brasileira prevalece à ênfase nas relações pessoais que convida à participação de todos na discussão dos assuntos. No entanto, a participação não envolve necessariamente atribuição de responsabilidade aos indivíduos, pois existe um alto grau de paternalismo na sociedade brasileira que resulta na postura de espectador (transferência de responsabilidade por parte dos subordinados para as lideranças) e no medo de errar.

Em um trabalho realizado por esta autora, são sintetizados alguns depoimentos de brasileiros que ilustram este ponto de vista:

Dentro do grupo brasileiro estudado, o medo de arriscar e de arcar com a responsabilidade da decisão acabam induzindo a uma busca por consenso, a qual favorece as decisões em grupo. Os informantes declararam que gostam que o chefe dê a sua opinião e se sentem motivados com isso. Entretanto, quando os problemas tomam maiores proporções, os chefes são envolvidos na tomada de decisão, pois os indivíduos preferem não fazer nada com medo de perder os seus empregos, evitando tomar a decisão. [...] Assim, de um modo geral, parece que no Brasil todos gostam de participar das decisões, mas a tomada de decisão deve ser do chefe (FONSECA, 1997 apud FONSECA, 2007, p.13). grifo nosso. 


\subsection{Avaliação de programas ("medo de errar")}

Autores como Garrison e Noreen (2001) e Horngren et al. (2004) recomendam que seja aplicado no orçamento o conceito de 'contabilidade por responsabilidade', isto é, os gerentes devem ser responsáveis apenas pelos itens que eles possam de fato controlar. Garrison e Noreen (2001, p. 263) afirmam que "alguém precisa ser responsável por cada custo, ou, caso contrário, ninguém será responsável, e o custo inevitavelmente fugirá ao controle".

Essa personalização das responsabilidades permite que cada gerente seja analisado individualmente, com base nas variações dos itens sob sua responsabilidade. Quanto a isso, Garrison e Noreen (2001, p. 263) destacam que "não deve surpreender que os gerentes levem muito a sério o processo de orçamento e empreguem considerável energia, e mesmo emoção, para assegurar que os seus interesses e os interesses dos seus departamentos sejam resguardados". Várias situações de conflito podem ser criadas pela falta de facilidade de identificação dos responsáveis por variações no orçamento, quanto a isso, Horngren (2000, p.135) acredita que:

Ao analisar as variâncias, os gerentes deveriam dar mais importância a quem deve ser questionado, e não a quem deve se atribuir a culpa. Variâncias apenas sugerem indagações ou atenção direta às pessoas que devem possuir informações importantes.

Conforme argumenta Fonseca (2007), as características da sociedade brasileira não parecem proporcionar um ambiente adequado ao uso de medidas quantitativas. A cultura brasileira, conforme apontado por alguns pesquisadores, apresenta uma facilidade de lidar com a ambiguidade, sugerindo uma capacidade de lidar com informações pouco precisas, não contemplados nas medidas contábeis. A ênfase nas pessoas em detrimento das tarefas, conforme assinala Fonseca (2007), não parece consistente com a racionalização da organização de forma sequencial, em que as pessoas são vistas como custos e despesas. 
Por outro lado, a imputação de responsabilidades pelo cumprimento (ou não) dos objetivos traçados pelos orçamentos, na análise da cultura brasileira contrasta com a característica, "medo de errar". Segundo Tanure (2005), o desejo de acertar sempre e ser aceito pelo grupo faz parte da expectativa e necessidade do liderado frente ao "grande poder". Em culturas coletivistas como a brasileira, pressupõe-se que estes não sejam cometidos sozinhos, pois as relações profissionais se misturam com as pessoais, tornando-se parte do círculo de amizades e os erros são então mais tolerados. Conforme Fonseca (2007), a suposição é de que grupos são mais seguros do que indivíduos, sendo inapropriado responsabilizar um indivíduo por falha em sua performance, já que o destino, ao invés da competência, determina os resultados.

\subsection{Avaliação de desempenho e recompensa}

Uma das questões discutidas é a vinculação do orçamento a um sistema de avaliação por desempenho e recompensa. Rocha e Rocha (2006) discutem que alguns autores consideram o sistema de recompensa pelo desempenho uma das fontes de problemas para um programa orçamentário, enquanto outros autores acreditam que recursos financeiros são motivadores reais para os empregados submetidos a este sistema.

Frezatti (2006, p.48) afirma que:

Não apenas o desempenho negativo deve ser evidenciado. A ênfase sobre o desempenho negativo cria a percepção de que o orçamento só existe para punir os executivos. Quando a organização identifica as variações favoráveis e desfavoráveis, relacionando tal desempenho a uma área e a um indivíduo e proporcionando consequências na remuneração, ela proporciona condições de motivação adequada às pessoas. 
Segundo Jensen (2001), uma das fontes de problemas para um programa orçamentário é o sistema de recompensa pelos desempenhos, onde geralmente os gestores passam a ganhar bônus progressivos. De acordo com o autor, tal sistema cria incentivos para burlar o programa. Os gerentes começam a desenvolver artimanhas para melhorarem seus indicadores. Por exemplo, se o bônus de um gestor está ligado ao lucro de certa unidade, ele pode passar a postergar os gastos (por meio da manutenção de baixos estoques de matérias-primas ou adiamento de renegociações contratuais) e adiantar as receitas (via promoções especiais aos clientes), maximizando assim o lucro do exercício corrente. Se o gerente concluir que não irá alcançar a meta estabelecida, ele pode tentar passar a receitas para o exercício futuro e despesas para o atual, de forma que no próximo período seu resultado fique mais fácil de ser alcançado.

Jensen (2001) destaca ainda outras práticas de cunho ilícito, como falsificação de previsões e manipulação de informações importantes. E afirma que "uma vez que os gerentes têm consciência de que todos estão tentando 'jogar' com o sistema por razões pessoais, está criada uma organização repleta de cinismo, suspeitas e desconfiança" (JENSEN, 2001, p. 89).

Atkinson et al. (2000) propõem uma classificação para as espécies de recompensas, que aponta para o estabelecimento de recompensas intrínsecas e extrínsecas. As intrínsecas estariam ligadas à satisfação do funcionário ao executar uma tarefa e da oportunidade de crescimento que tal atividade oferece. Já as recompensas extrínsecas estariam baseadas no desempenho, e poderiam se configurar desde gratificações em dinheiro a placas de homenagem, passando por viagens e ações da empresa. Esse autor acredita que em função da amplitude do debate existente em torno da eficiência de cada um dos tipos de recompensa, as de caráter financeiras (extrínsecas) tendem a ser baseadas em sistemas formais, com estruturas claras e diretrizes bem definidas.

Com relação à vinculação do sistema de recompensas ao desempenho, na visão de Anthony e Govindarajan (2002, p.613), "a concessão de incentivos é um mecanismo 
importante para encorajar e motivar executivos a atingirem os objetivos da organização", que no caso em questão, concentra-se nos orçamentos.

No entanto, presume-se que os indivíduos se sentem motivados por desafios e esperam ser recompensados ao atingirem os objetivos traçados. A motivação implícita seria por realização a qual pressupõe uma vontade de aceitar riscos e uma preocupação com performance (HOFSTEDE, 1997).

O contraponto é que pesquisadores como Tanure e Prates (1996), Hofstede (1997), Fonseca (2007), argumentam que a sociedade brasileira apresenta características culturais bastante diversas das apresentadas, como certa aversão ao risco (medo de perder os empregos) e uma preferência por práticas mais coletivistas, nas quais as "práticas de compensação presentes indicam a preferência por compensações para diluir o risco e fazer justiça social" (FONSECA, 2007, p. 15), de forma que os incentivos individuais não são práticas de gestão tão bem aceitas em sociedades como a brasileira.

\section{CONSIDERAÇÕES FINAIS}

O trabalho em questão buscou apresentar as principais características do orçamento, bem como as possibilidades básicas de formulação e uma apreciação dos aspectos conceituais, comportamentais e culturais envolvidos no programa orçamentário.

Notoriamente, pode-se constatar a partir da revisão bibliográfica apresentada que o orçamento apresenta forte vínculo com o planejamento estratégico das companhias e este componente é essencial para o êxito das empresas. A literatura apresentada é bastante rica e percebe-se inclusive que os autores pesquisados contemplam em seus trabalhos toda a preocupação premente com a necessidade de envolvimento dos gestores e colaboradores, sobre a aderência do orçamento (mais autoritário ou participativo), sobre a aplicação de avaliação de desempenho vinculada e suas consequências, dentre outros aspectos. 
Em suma, as preocupações expostas reforçam quanto à atenção a ser dispensada às diferenças entre as culturas de origem, na qual as ferramentas gerenciais são desenvolvidas, - em especial, a cultura norte americana - e a cultura brasileira que parece ser fator determinante no sucesso da implantação do modelo. Tanure e Rodrigues (2001) observam que há uma tendência à importação dos modelos de gestão americanos especialmente em non US-companies, o que significa uma perda de capacidade de melhor competir, visto que dificilmente outro país usará com tamanha qualidade os modelos americanos de gestão como os próprios Estados Unidos, que têm aderência às premissas básicas das teorias formuladas em seu país.

Para fins acadêmicos, nos cursos gerenciais que abordam amplamente o estudo dos orçamentos, cabe frisar o quão importante é ampliar a análise desta ferramenta gerencial fundamental e presente nas organizações, contemplando todas as nuances existentes em função dos aspectos comportamentais e culturais que devem ser respeitadas para o sucesso da sua implantação.

\section{REFERÊNCIAS}

ADLER, N. J. (1991). International dimensions of organizational behaviour. Califórnia, Wadworth Publishing Company. in FONSECA, A. C. P. D. Sistemas de controle gerencial e cultura brasileira: uma análise do modelo de Anthony. ABCustos Associação Brasileira de Custos, v. 2, n. 1, jan/abr 2007.

ATKINSON, A. A. et al. (2000). Contabilidade Gerencial. São Paulo: Atlas.

ANTHONY, R. N.; GOVINDARAJAN, V. (2002). Sistemas de Controle Gerencial. São Paulo: Ed. Atlas.

CARDOSO, R. L.; MÁRIO, P. C.; AQUINTO, A. C. B. (2007). Contabilidade Gerencial. Atlas.

FONSECA, A. C. P. D. (2007). Sistemas de controle gerencial e cultura brasileira: uma análise do modelo de Anthony. ABCustos - Associação Brasileira de Custos, v. 2, n. 1 , jan/abr.

FREZATTI, F. (2000). Orçamento Empresarial. (2 ed.). São Paulo: Atlas. 
Aspectos conceituais, comportamentais e culturais do orçamento como ferramenta gerencial Adriane Fagundes Silva, Jair Nunes

Paulo: Atlas.

(2006). Orçamento Empresarial: planejamento e controle gerencial. São

GARRISON, R. H.; NOREEN, E. W. (2001). Contabilidade Gerencial. (9 ed.). Rio de Janeiro: LTC.

GOMES, J. S.; SALAS, J. M. A. (2001). Controle de Gestão: Uma abordagem contextual e organizacional. (3 ed.). São Paulo: Ed. Atlas.

HAMPDEN-HAMPDEN-TURNER, C. e TROMPENAARS, F. (1994). The seven cultures of capitalism. London, Piatkus. in FONSECA, A. C. P. D. Sistemas de controle gerencial e cultura brasileira: uma análise do modelo de Anthony. ABCustos - Associação Brasileira de Custos, v. 2, n. 1, jan/abr 2007.

HOFSTEDE, G. (1997). Culturas e Organizações. Tradução de Antonio Fidalgo. (1 ed.). Lisboa: Ed. Silabo.

HORNGREN, C. T. (2000). Contabilidade de Custos. (9 ed.). LTC: Rio de Janeiro.

São Paulo: Prentice Hall.

; (2004). SUNDEM, G. L.; STRATTON, W. Contabilidade gerencial.

JENSEN, M. C. (2001). O orçamento não funciona. Vamos consertá-lo. Havard Business Review. São Paulo, ed. 764, p. 85-93.

LEITE, R. M. et. al. (2008). Orçamento empresarial: Levantamento da Produção Científica no Período de 1995 a 2006. R. Cont. Fin. USP. São Paulo, v. 19, n 47, p: 5672.

MARTINS, A. M. S. O.; LONGARY, A. A.; BEUREN, I. M. (2005). Características do Sistema Orçamentário Adotado nas Maiores Empresas Industriais Catarinenses. Revista Pensar Contábil. Rio de Janeiro, v. 7, n 28, p: 5-12.

PADOVEZE, C. L. (2005). Planejamento orçamentário. São Paulo: Pioneira/Thonsom Learning.

ROCHA, T. P. M; ROCHA, D. P. M. (2006). Os aspectos comportamentais na gestão do orçamento. São Paulo: 9o SEMEAD. [acesso em 10 de dezembro de 2011]. Disponível http://www.ead.fea.usp.br/Semead/9semead/resultado_semead/an_resumo.asp? cod_trabalho=407. 
SILVA, A.F.S. (2010). Consideração do elemento cultural no desenho do controle de gestão das empresas estrangeiras. 166 f. (Dissertação de Mestrado). Faculdade de Administração e Finanças, Universidade do Estado do Rio de Janeiro, Rio de Janeiro.

SANVICENTE, A. Z.; SANTOS, C. da C. (2000). Orçamento na administração de empresas: planejamento e controle. São Paulo: Atlas.

TANURE, B.. (2005). Gestão à brasileira: somos ou não diferentes? Uma comparação entre América Latina, Estados Unidos, Europa e Ásia. São Paulo: Atlas.

.; RODRIGUES, S. B. (2001). Compreendendo a dimensão cultural. In: Tanures, B (org) Fusões, aquisições e parcerias. (1 ed.). São Paulo, Atlas, v. 1 p. 103123

; PRATES, M. A. S. (1996). O estilo brasileiro de administrar: sumário de um modelo de ação cultural brasileiro com base na gestão empresarial. São Paulo: Atlas.

TUNG, N. H. (1994). Orçamento empresarial e custo-padrão. (4 ed.). São Paulo: Universidade Empresa.

VASCONCELOS, Y. L. (2006). Implementação do processo orçamentário nas organizações: uma abordagem prática. Revista Brasileira de Contabilidade. Jan/Fev 2004. Brasília, n.145 p.54-71. in ROCHA, T.P.M; ROCHA, D.P.M. Os aspectos comportamentais na gestão do orçamento. São Paulo: SEMEAD. [acesso em 10 de dezembro de 2011]. Disponível http://www.ead.fea.usp.br/Semead/9semead/resultado_semead/an_resumo.asp? cod_trabalho=407.

WELSCH, G. A. (2006). Orçamento Empresarial: planejamento e controle do lucro. 4a ed. São Paulo: Atlas, 1983 in ROCHA, T.P.M; ROCHA, D.P.M. Os aspectos comportamentais na gestão do orçamento. São Paulo: 9o SEMEAD. [acesso em 10 de dezembro de 2011]. http://www.ead.fea.usp.br/Semead/9semead/resultado_semead/an_resumo.asp? cod_trabalho $=407$.

ZDANOWICZ, J. E. (2005). Orçamento operacional: uma abordagem prática. Porto Alegre: Sagra 1984 in MARTINS, A. M. S. O.; LONGARY, A. A.; BEUREN, I. M. Características do Sistema Orçamentário Adotado nas Maiores Empresas Industriais Catarinenses. Revista Pensar Contábil. Rio de Janeiro, v. 7, n 28, p: 5-12. 
Aspectos conceituais, comportamentais e culturais do orçamento como ferramenta gerencial Adriane Fagundes Silva, Jair Nunes

Data de Submissão: 18/10/2012

Data de Aceite: 22/12/2012 